DOI: https://doi.org/10.17648/2238-037X-trabedu-v28n3-15933

\title{
UM PERFIL DE EGRESSOS DO CURSO DE EdUCAÇÃo FÍSICA DA UNIVERSIDAdE FEDERAL DE MinAS GERAIS ${ }^{1}$
}

\author{
Egress Profile from the Physical Education course of the Universidade Federal \\ de Minas Gerais
}

FURTADO, Renan Monticeli² ISAYAMA, Hélder Ferreira ${ }^{3}$

\begin{abstract}
Resumo
Este estudo investigou o perfil dos egressos formados em Educação Física na Universidade Federal de Minas Gerais, no período de 2011 a 2017. Metodologicamente utilizamos a aplicação de um questionário semiestruturado disponibilizado na plataforma eletrônica Google Docs, através da ferramenta Formulários Google e para analise dos dados foi utilizado à ferramenta Planilhas Google. 101 egressos responderam e participaram da pesquisa e os dados demonstram que os campos de atuação com maior intervenção dos egressos são: Escola (22\%), Personal Trainer (17,4\%), Academias de Ginástica (14,4\%), Escolinhas de esporte (12,9\%) Treinamento funcional $(6,8 \%)$, Alto rendimento esportivo $(5,3 \%)$ e recreação $(3,8 \%) .50 \%$ dos egressos se formaram como bacharéis, $30 \%$ como licenciados e $20 \%$ possuem as duas formações, sendo que, $35 \%$ dos egressos optaram por completar a formação e realizar pós-graduação latu sensu e/ou stricto sensu e $65 \%$ não realizou pós-graduação.
\end{abstract}

Palavras-chave: Egressos. Mercado de trabalho. Educação Física.

\section{ABSTRACT}

This study investigated the profile of graduates graduated in Physical Education at the Federal University of Minas Gerais from 2011 to 2017. Methodologically we used the application of a semistructured questionnaire made available in the electronic platform Google Docs, through the Google Forms tool and for analysis of the data was used to the Google Sheets tool. 101 graduates answered and participated in the research and the data show that the fields of action with the greatest intervention of the graduates are: School (22\%), Personal Trainer (17.4\%), Gymnastics Academies $(14.4 \%)$, sport (12.9\%) Functional training $(6.8 \%)$, High sports performance $(5.3 \%)$ and recreation (3.8\%). $50 \%$ of graduates graduated as graduates, $30 \%$ as graduates and $20 \%$ have both training courses, $35 \%$ of graduates chose to complete the training and to perform post-graduation latu sensu and / or stricto sensu and $65 \%$ did not perform postgraduate studies.

Keywords: Graduates. Labor Market. Physical Education.

\footnotetext{
${ }^{1}$ Esse texto é parte de Trabalho de Conclusão do Curso Bacharelado de Educação Física da UFMG.

${ }^{2}$ Mestrando em Estudos do Lazer pela UFMG, Graduação em Educação Física pela UFMG. E-mail: renanfurtado14@hotmail.com.

${ }^{3}$ Pós-Doutor em Educação pela UFRJ. Doutor em Educação Física pela Unicamp, Mestre em Educação Física pela Unicamp, Graduação em Educação Física pela UNESP/Rio Claro. Docente da UFMG e do Programa de Pós-Graduação em Estudos do Lazer Email: helderisayama@yahoo.com.br.
} 


\section{INTRODUÇÃO}

Nos últimos anos verificamos aumento significativo no número de Cursos de Graduação em Educação Física e consequentemente o número de profissionais formados e isso tem propiciado a ampliação e diversificação do mercado e alterações nas condições de trabalho do profissional, apontando a necessidade de mais estudos analisando o perfil do egresso no curso de Educação Física. Segundo EMEC (2015) existem cerca de 1.452 cursos de Educação Física pelo país e quando comparados os dados coletados em 2008 em relação a 2014, Leite et al. (2015) observaram um aumento de $78,16 \%$ no total de cursos.

Apesar dos poucos estudos sobre egressos na Educação Física, Piccoli, (2004) analisa o "Perfil do egresso do curso de Educação Física do Centro Universitário Feevale" e nos apresenta dados do período de 1976 a 2000. O objetivo do estudo foi conhecer as características dos egressos dos alunos do centro universitário dentro do período analisado, sendo este período da primeira turma formada até os alunos que concluíram o curso no ano 2000. A investigação revelou que os egressos do Curso de Educação Física do período de 1976 a 2000 se dividiam em atuar como professor na escola ou atuar em outras atividades. Em relação à remuneração, 58,5\% afirmam que o cargo ocupado não era compatível com o salário, levando o profissional a trabalhar em mais de um emprego. Os baixos salários levavam os profissionais à procura de empregos fora da área de atuação do professor de Educação Física e também em setores não formais, chegando até o abandono da profissão para se especializarem em setores com maiores chances de satisfação financeira.

É interessante analisar e comparar com a atual realidade do profissional de Educação Física, pois, mesmo passando-se alguns anos ainda vivemos uma realidade próxima a esta relatada no estudo. A insatisfação com o salário foi observada, e Piccoli (2004) conclui relatando a necessidade de salários dignos para que os profissionais continuem motivados a trabalhar com qualidade, mas ressalta a necessidade de especialização para se destacar no mercado de trabalho. Apesar deste estudo apresentar dados importantes ao egresso, é necessário atualizar estas informações, pois, hoje em dia o egresso do profissional de Educação Física mudou, a começar pelos percursos curriculares, licenciatura e bacharelado, que formam profissionais em diferentes campos de atuação. E também destacamos as mudanças tanto no mercado de trabalho, comportamento da sociedade, e a economia do país.

Até 1987 o curso de Educação Física oferecia a modalidade Licenciatura Plena, com isso o profissional ao sair da universidade poderia trabalhar no âmbito escolar e fora dele nas academias, clubes, hospitais, etc. Após a divisão de modalidades Licenciatura e Bacharelado os campos de atuação também se dividiram e para Morschbacher (2012) a divisão entre dois cursos era necessária, pois o mercado de trabalho havia se expandido e também pelas mudanças na legislação que se dizia respeito à formação de professores para a atuação na educação básica. Taffarel (2012) considera que o objetivo desta fragmentação é desregulamentar o trabalho por meio do ajuste especializado da formação inicial, e que isso fragiliza o trabalhador pelo esvaziamento teórico e delimitação nos campos de trabalho.

Jacob et al. (2017) investigou as demandas relativas à formação encontradas pelos egressos de Educação Física nas modalidades Licenciatura e Bacharelado quando entraram para o mercado de trabalho, e também buscou entender o motivo pelo qual 
os estudantes egressos retornam para complementar sua formação no outro curso de graduação em Educação Física. Foi apurado o depoimento de egressos durante o período de 2008 a 2015 dos alunos que optaram por realizar as duas modalidades. Os relatos afirmam que a formação inicial apresentam diversas lacunas, como citado por um professor da Licenciatura, que sentiu falta de conteúdos que abordassem ciências biológicas nas disciplinas cursadas. O Bacharel em Educação Física sentiu que a abordagem teórico-pedagógica do seu curso não foi o suficiente para uma boa formação.

Em relação ao mercado de trabalho, o estudo de Jacob et al. (2017) identificou que tanto os licenciados quanto os bacharéis sentem a necessidade de fazer a continuidade de estudos para complementar o currículo. E o que gera maior interesse na formação na Licenciatura é que a modalidade oferece maior estabilidade financeira por conta de concursos públicos e a formação no Bacharelado abrange mais opções para atuar como profissional. Logo, o estudo constatou através do depoimento dos egressos que a divisão do curso em Licenciatura e Bacharelado desqualificou a formação profissional e fragmentou os campos de conhecimento dos respectivos cursos. E que a formação unificada agregaria mais conhecimento e facilitaria o ingresso dos profissionais no mercado de trabalho.

Para Vargas (2011) a inserção do egresso no mercado de trabalho oferece diferentes remunerações e possibilidades de progresso profissional. Contudo, essas possibilidades não dependem apenas de se formar em uma universidade, elas estão atreladas ao gênero, à etnia, à classe social, à rede de relações sociais, etc. Por isso, o fato do egresso possuir um certificado de conclusão de uma graduação não garante a ele um emprego e remuneração condizentes com a formação recebida.

Os estudos realizados com os egressos após o fim da graduação buscam pesquisar o perfil do profissional formado, campo de atuação, situação do mercado de trabalho, renda, remuneração. Em alguns casos, além de pesquisar estas variáveis o estudo abrange para a perspectiva do egresso em relação ao curso, ou seja, a avaliação da formação que foi recebida e as competências desenvolvidas durante a graduação. De acordo com (SOUZA, 1999), o objetivo principal da avaliação das Instituições de Ensino Superior é promover a melhoria do ensino e da aprendizagem. Logo, a intenção deste tipo de estudo é contribuir com as discussões acerca da realidade profissional do egresso e fornecer informações às propostas de mudança curricular do curso estudado. Para Lousada e Martins (2004), a avaliação do curso contribui para que as instituições de ensino superior repensem suas práticas administrativas, técnicas e pedagógicas, de forma crítica e comprometida, refletindo sobre o seu papel na sociedade como promotora do saber capaz de compreender e de modificar a realidade. Schwartzman e Castro (1991) consideram que o estudo do egresso recupera questões relacionadas à formação recebida durante o curso, particularmente as ligadas à qualidade do ensino e adequação dos currículos à situação profissional.

Nos dias de hoje o mercado de trabalho procura profissionais cada vez mais preparados, que possam transmitir conhecimento e dominar técnicas multidisciplinares. Para (GONDIM, 2002) o desenvolvimento científico e tecnológico, suporte fundamental da globalização, aumenta a complexidade do mundo e passa a exigir um profissional com competência para lidar com um número expressivo de fatores. Muita das vezes o egresso entra no mercado de trabalho com diversas inseguranças e sem saber ao certo como funciona este sistema para alcançar o sucesso profissional. 
Podemos observar através das pesquisas analisadas a importância do estudo do perfil egresso para obtermos informações sobre as características dos profissionais formados. Portanto, este estudo visa traçar um perfil da atuação profissional do universo de egresso do curso de Educação Física da UFMG. Desta forma, este estudo teve por objetivo analisar os aspectos relacionados á atuação profissional (áreas de atuação, tendências do mercado, renda, etc.), avaliando os professores de Educação Física formados na UFMG, no período de 2011 a 2017.

\section{Caminhos Metodológicos}

Essa é uma pesquisa descritiva, pois se tem como objetivo a descrição das características de uma determinada população (GIL, 2008), no caso os egressos do curso de Educação Física da UFMG. Foram utilizados como instrumentos da pesquisa o levantamento bibliográfico e a pesquisa de campo.

Os sujeitos participantes da pesquisa foram 101 egressos formados entre 2011 e 2017 no curso de Educação Física da Universidade Federal de Minas Gerais, localizado em Belo Horizonte. Foi enviada ao colegiado e a sessão de ensino do curso de Educação Física da EEFFTO uma solicitação por meio de carta do endereço eletrônico de todos os formandos em licenciatura e bacharelado, porém, a sessão de ensino do curso obtinha os endereços eletrônicos somente dos egressos formados no período de 2011 à 2017, sendo este o motivo para não estudarmos os anos anteriores a 2011.

Para a realização da pesquisa de campo foi utilizado um questionário semiestruturado com 28 questões dividas em três eixos norteadores: dados pessoais dos egressos, informações sobre a formação profissional oferecida pela UFMG durante a graduação e o mercado de trabalho. Anexo ao questionário o Termo de Consentimento Livre e Esclarecido (TCLE) que autoriza a utilização dos dados coletados e garante a eles o total sigilo de sua identidade.

A aplicação do questionário ocorreu por meio da plataforma eletrônica do Google, o Google Docs, através da ferramenta Formulários Google no período de 26 de março a 15 de abril de 2018. Após receber os endereços eletrônicos dos sujeitos da pesquisa pela sessão de ensino do curso de Educação Física da UFMG, foi enviado no total 444 e-mails para os egressos com o questionário e as informações necessárias para participar da coleta. Dos 444 egressos convidados a participar da pesquisa, 101 responderam o questionário, o que significa um total de $22,95 \%$ de retorno.

Após os dados coletados, os mesmos foram lançados na ferramenta Planilhas Google, gerando os dados em porcentagem das respostas dos egressos ao questionário. Esses dados foram analisados e cruzados de acordo com as possibilidades de resposta para as questões norteadoras dessa pesquisa.

\section{OS EgRESSOS do curso de EduCAÇÃo FísıcA dA UFMG NO MERCAdo de TRABALHO}

Através dos dados extraídos pelo questionário aplicado na pesquisa de campo, os resultados serão primeiramente apresentados de acordo com os três eixos norteadores determinados no questionário, que são: características dos sujeitos, formação profissional e atuação profissional no mercado de trabalho, e posteriormente 0 cruzamento das variáveis encontradas no questionário. 
É valido ressaltar que algumas questões do questionário apresentavam mais de uma alternativa para resposta e as questões do eixo norteador "atuação profissional e mercado de trabalho" não são direcionadas para os egressos que não estão atuando como profissionais da área da Educação Física. Desta forma, a frequência absoluta (o número de vezes em que uma determinada variável assume um valor) e os valores em porcentagem (\%) apresentaram diferenças de acordo com a questão analisada.

No total participam desta pesquisa 101 egressos do curso de Educação Física da Universidade Federal de Minas Gerais, dos quais $68 \%$ dos sujeitos são do sexo feminino e $32 \%$ do sexo masculino.

As idades dos egressos variam entre 22 e 40 anos, sendo que $79 \%$ apresentam idade entre 22 e 30 anos, indicando um perfil de trabalhador jovem, levando em consideração que a maior parte da amostra se formou em 2011, há sete anos. As taxas de participação dos jovens no mercado de trabalho são altas, e pode ser justificada pela "onda jovem" decorrente do nascimento de um grande número de pessoas nas ultimas décadas com significativos contingentes de indivíduos ainda jovens ingressando maciçamente na força de trabalho (CHAHAD, 2003).

Mesmo apresentando um perfil jovem os egressos do curso de Educação Física da UFMG vivem em uma época onde a exigência de qualificação e a necessidade de especialistas para lidar com a demanda do mercado tem feito o período de preparação para a vida adulta se tornar mais longo, pela imposição do mercado a conclusão do curso superior e suas posteriores especializações (MELO e BORGES, 2007). O perfil jovem dos profissionais da Educação Física pode ser justificado pelo ingresso cada vez mais cedo dos universitários nas instituições de ensino superior, levando a uma formação profissional e inserção no mercado de trabalho precoce.

Em relação à cor/raça dos egressos pesquisados, $50 \%$ dos sujeitos se consideram brancos $37 \%$ se consideram pardos e $8 \%$ se consideram pretos.

É necessário ressaltar que as menores porcentagens de raça dos egressos encontradas são dos negros, mesmo com a grande proporção de pardos e negros na sociedade brasileira e com a implementação do sistema de cotas para o ingresso na universidade ainda se vê poucos deles conseguindo entrar ou se manter em cursos superiores. Culturalmente apresentam hegemonia da raça branca em sua totalidade, seja dos alunos ingressos na universidade, como também do corpo de professores das instituições. Grandes universidades brasileiras podem ser usadas como exemplo para expor o fato, a USP com os seus 4700 professores tem menos de 10 docentes negros, ou seja, menos de $1 \%$ do total de professores da instituição (CARVALHO, 2005).

A maioria dos egressos residem na região metropolitana de Belo Horizonte $(91 \%)$, sendo $70 \%$ na capital mineira, Belo Horizonte, lugar onde se localiza a sede da UFMG, $11 \%$ em Contagem, $3 \%$ dos egressos residem atualmente em São Paulo, e o restante da amostra se divide em outras cidades dentro e fora do Brasil, porém, com predominância de cidades de Minas Gerais.

Sobre os dados acadêmicos dos egressos do curso de Educação Física da UFMG, o que mais os influenciou na escolha da graduação foi à diversidade de áreas de atuação que o curso proporciona (34,7\%). O fato de muitos egressos terem sido atletas antes de ingressar na universidade também foi um motivo que influenciou na escolha da Educação Física como profissão (27,7\%). A afinidade dos egressos com atividades físicas e esportes no geral influenciou $11,9 \%$ dos egressos a escolherem o curso de 
Educação Física, e a afinidade com as áreas de atuação oferecidas pelo curso gerou interesse em 10,9\% dos egressos na graduação oferecida pela UFMG. Fica claro através dos resultados que a escolha do curso esta relacionada com as possibilidades de atuação que a profissão proporciona e a afinidade dos ingressantes com atividade física e esportes, por terem sido atletas ou praticantes de atividade física.

\section{Gráfico 1 - Motivos que levaram os egressos do curso de Educação Física da UFMG a escolher a Educação Física como profissão}

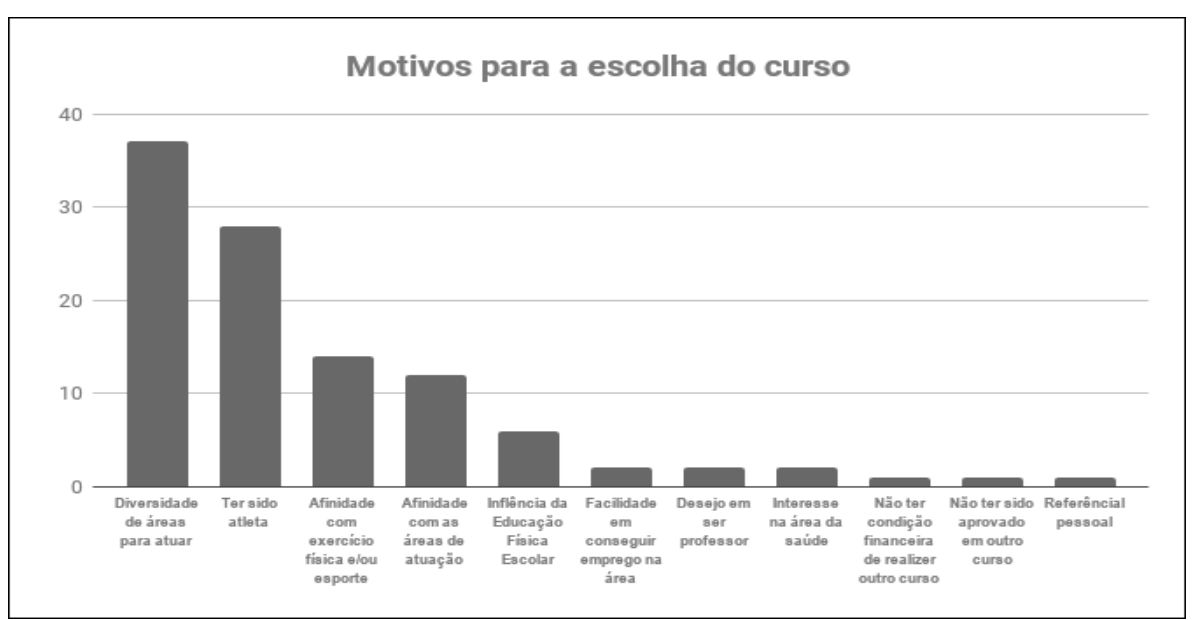

Fonte: Elaborado a partir dos dados da pesquisa (2018)

Os estudos de RAZEIRA et al. (2014); MASCHIO et al. (2008); KRUG e KRUG (2008) apresentam resultados que vão ao encontro com esses dados, onde as motivações para a escolha da Educação Física como profissão estão diretamente ligadas ao interesse e afinidade pelas múltiplas áreas de atuação e gosto pessoal pela prática de atividades físicas e esportivas.

$5,9 \%$ dos egressos da UFMG foram influenciados pela Educação Física escolar na hora de escolher a profissão, para Almeida e Fensterseifer (2007) a relação com a Educação Física escolar pode ser um dos motivos que levam alguém a escolher a Educação Física como profissão. A influência da Educação Física escolar pode ser atribuída ao modelo desportivo e tecnicista utilizado por muitos professores, estimulando ainda mais o gosto pelo esporte em alunos que já se interessavam pela área.

Pode-se observar também que apenas $2 \%$ dos egressos escolheram o curso porque desejavam ser professores, o desinteresse pela profissão "professor (a)" é uma realidade em todo o Brasil, onde os baixos salários, as condições precárias de trabalho, a falta de segurança nas escolas, o desprestigio social e a falta de perspectiva na carreira são alguns dos motivos que justificam o menor numero de ingressos nas universidades. A evasão discente também ocorre com frequência dentro da graduação, na UFMG a evasão em cursos de licenciatura é maior que $60 \%$, e o problema está relacionado com o baixo prestigio social e financeiro que acomete as licenciaturas (LIMA e MACHADO, 2013). Estes dados representam de forma simbólica a falência da educação básica no país, onde os professores, profissionais que detém conhecimento não são valorizados pelo governo e pela população. Com isto, o desprestígio da profissão e as condições precárias de trabalho ganham força e fazem com que se formem menos professores como apontam as informações coletadas. 
Em relação à formação acadêmica, $82 \%$ dos egressos estão satisfeitos com a formação profissional oferecida pelo curso, tendo então uma boa aceitação da população pesquisada, sendo que $18 \%$ da amostra considera que o curso não atendeu suas expectativas. Se tratando de mercado de trabalho e atuação profissional, $50 \%$ dos egressos se sentiam razoavelmente preparados para trabalhar quando se formaram, $38 \%$ afirmou estarem preparados e apenas $12 \%$ se considera pouco ou não preparados para trabalhar. Quando se trata dos estágios obrigatórios ofertados pelo curso, $84 \%$ dos egressos consideram que esta pratica contribuiu para a sua formação como profissional de Educação Física, sendo que 16\% não consideram os estágios obrigatórios um fator contribuinte para a sua formação.

Desta forma, podemos dizer que a percepção dos egressos quanto à formação oferecida pela UFMG é positiva, já que, a maioria dos egressos se sentiam preparados para trabalhar, estavam satisfeitos com a formação profissional e consideram que os estágios obrigatórios do curso contribuíram para sua formação como profissional. A avaliação positiva da formação profissional oferecida pelo curso de Educação Física da UFMG se difere de outros estudos que avaliam a percepção dos graduandos e egressos sobre a formação oferecida pelas instituições. Melo e Borges (2007) analisaram a percepção da transição universidade-mercado de trabalho e encontraram que $47,4 \%$ dos egressos estudados consideram inadequada a formação oferecida pela universidade no qual se formaram e $21,1 \%$ não se sentia preparado para a rotina de trabalho.

A maioria dos egressos participantes da pesquisa se formou em 2011 (24\%) e 2017 (17\%). $50 \%$ dos egressos realizaram apenas a formação de bacharel em educação física e 30\% dos egressos são licenciados. A menor representação dos egressos formados em licenciatura corrobora com estudos de Trindade (1996) que verificou que a primeira opção de atuação profissional dos alunos de Educação Física é o treinamento esportivo e de Tani (1996) quando afirma a redução da demanda de professores atuando nas escolas. O resultado encontrado na questão do questionário aplicado na pesquisa sobre as influências na hora de escolher a profissão também vão ao encontro com estes fatos, quando se observa pequenas porcentagens relacionadas ao desejo dos egressos em serem professores (1,9\%) e as influências da educação física escolar (5,7\%). Apenas $20 \%$ dos egressos se formaram como bacharel e licenciado sendo um valor relativamente baixo pensando que para concluir as duas graduações não se fazem necessário a realização de um novo processo seletivo.

Quando se trata da educação continuada após a graduação, 35\% dos egressos optaram por realizar pós-graduação latu sensu e stricto sensu, sendo que $65 \%$ da população não realizou nenhuma pós-graduação.

Apesar da pós-graduação não ter sido opção para a maioria dos egressos da Educação Física na UFMG, é valido ressaltar o notável crescimento do sistema de pósgraduação strito sensu no Brasil. Em 2001 o país tinha em torno de 26.000 mestres e doutores, e em 2010 chegou a aproximadamente 53.000. Apenas em 2010, mais de 12.000 foram titulados doutores e 41.000 mestres concluíram a pós-graduação (MTC, 2010). Através destes dados pode-se dizer que a pós-graduação é uma possível tendência no meio acadêmico e no mercado de trabalho, que aumenta cada vez mais as exigências e valoriza o profissional com maior qualificação. Dentro dos egressos que fizeram pós-graduação, 59,5\% optaram pela especialização, 33\% optaram pelo mestrado e $7,1 \%$ realizaram doutorado. 
Buscando entender a razão pelo qual os egressos optaram por fazer a pós-graduação, foi encontrada que $50 \%$ dos egressos decidiram realizar a pós-graduação para complementar a sua formação profissional, $21,2 \%$ acreditam que o mercado de trabalho exige cada vez mais profissionais com a formação mais completa e 21,2\% pretendem ser docente de nível superior. Observando este panorama podemos ver a necessidade do aprimoramento das competências de intervenção profissional, na tentativa de melhorar a qualidade dos serviços prestados e garantir espaço no mercado de trabalho.

Para Botomé e Kubo (2002) o papel dos programas de pós-graduação na universidade é de garantir ao país um potencial de produção de conhecimentos, tecnologia e aprendizagem de nível superior compatíveis com as exigências necessárias e com o desenvolvimento da ciência em âmbito internacional. Para Santos (1999) a educação continuada evita que o profissional se desatualize técnica, cultural e profissionalmente e que perca sua capacidade de exercer a profissão com competência. Desta forma, é notável a preocupação dos profissionais em se manterem atualizados com as novas descobertas cientificas para que possam realizar uma intervenção concreta e embasada, também cabe relatar que com a crescente competitividade no mercado de trabalho, muitos profissionais têm ofertado a pós-graduação como um diferencial, se tornando em alguns casos essenciais.

Se tratando do mercado de trabalho em Educação Física 79\% dos egressos participantes desta pesquisa estão trabalhando em sua área de formação acadêmica, enquanto $15 \%$ estão trabalhando em outras áreas e $6 \%$ estão desempregados. Outras pesquisas de perfil do egresso da Educação Física encontraram resultados semelhantes, Salles et al. (2015) identificaram que 91\% dos egressos do bacharelado e $83 \%$ dos egressos da licenciatura em Educação Física encontram-se inseridos no mercado de trabalho.

O setor com maior mão de obra dos profissionais da educação física é o setor privado $(62,9 \%)$, seguido do setor público $(32 \%)$ e do terceiro setor $(4,4 \%)$. Uma possível explicação para estes resultados é que a inserção profissional na esfera pública é mais difícil em comparação à esfera privada, levando em consideração que o setor público exige mão de obra mais qualificada e a entrada é concretizada, na maioria das vezes, por uma aprovação em concurso público (IPEA, 2009). Deixando claro que, não queremos dizer que o profissional de Educação Física não tem mão de obra qualificada ou capacidade de passar em um concurso publico, a fala apenas afirma que o setor público é menos acessível que o setor privado, e isto é uma possível explicação para a maior inserção dos profissionais no setor privado.

Quando analisado os dados referentes aos locais de trabalho onde os egressos estão inseridos profissionalmente, foi encontrado que $22 \%$ dos profissionais estão inseridos nas escolas. O estudo de Furtado e Santiago (2015) obteve resultado semelhante, demonstrando que a escola é o principal lócus de atuação dos egressos de Educação Física da Universidade Federal de Goiás. Steinhilber (1999) e Piccoli (2006) encontraram que a maioria dos egressos da Educação Física em suas respectivas universidades atuam fora do ambiente escolar. A maior porcentagem de egressos atuando nas escolas contradiz os dados obtidos nesta pesquisa que mostram que a maioria dos egressos são bacharéis, mas isto pode ser explicado pelo fato de que o bacharelado obtém diversas opções para inserção profissional no mercado de trabalho quando comparado à licenciatura, que tem sua formação voltada para a escola. Desta 
forma, os licenciados se direcionam a escola quando formados e os bacharéis se dividem em diversos campos de atuação. $17,4 \%$ dos egressos trabalham como personal trainer, 14,4\% trabalham em academias de ginástica, 12,9\% trabalham em escolinhas de esporte, 6,8\% trabalham com treinamento funcional, 5,3\% com alto rendimento esportivo e 3,8\% trabalham com recreação e lazer.

Outros campos de atuação também são citados pelos egressos, porém, com menor inserção dos profissionais: Saúde Publica (1,5\%), Gestão (1,5\%), Hospitais (1,5\%), NASF (1\%) Corpo de bombeiros (1\%), PELC (1\%), etc. O número de profissionais inseridos em hospitais ou trabalhando com a saúde publica é pequeno quando comparado com as outras áreas de atuação, corroborando com os estudos que alertam a falta de uma formação adequada para os profissionais da Educação Física atuar como profissionais da área da saúde, como já são considerados, mas não atuam. Prado e Carvalho (2016) relatam a falta de alinhamento da formação profissional dos egressos em Educação Física com os princípios norteados da saúde no Brasil, e sugerem uma formação que permita o profissional ser capaz de lidar com as implicações e decorrências de dilemas nas condições de saúde da população.

Em relação aos vínculos empregatícios 36\% dos egressos estão empregados com carteira assinada, enquanto $27 \%$ são autônomos, $9 \%$ esta com contrato temporário no lugar onde trabalha e 7\% dos egressos são proprietários da empresa.

Como podemos identificar a maioria dos egressos tem sua carteira assinada no local de trabalho onde está inserido, entretanto, existe também uma porcentagem considerável de egressos autônomos, trabalhadores do mercado de trabalho informal. Pesquisas constataram que o crescimento do mercado informal é acompanhado pelo declínio de trabalhadores com carteira assinada e pelo crescimento dos que trabalham sem registro. A ruptura de vínculos empregatícios formais representa para o trabalhador a renuncia de seus direitos e benefícios sociais, como $13^{\circ}$ salário e aviso prévio. Sendo considerados "cidadãos de segunda classe" estes trabalhadores perdem direitos garantidos pela constituição brasileira e apesar de alguns grupos considerarem que a remuneração recebida é justa, ela representa pouca coisa diante da perda de tantos direitos que o trabalho informal não oferece (JAKOBSEN et al., 2000; WERNECK, 2001).

A tendência de inserção destes profissionais em cargos de trabalho autônomos e em áreas de atuação no âmbito não escolar apresentam um crescimento significativo. Corroboram com este resultado Furtado e Santiago (2015) que relatam maior número de trabalhos autônomos dentro das academias, onde os profissionais trabalham como Personal Trainer. Os egressos da UFMG apresentam perfil semelhante, onde valores significativos de trabalhadores autônomos exercem o papel de personal trainer. Como podemos observar o trabalhador autônomo esta presente nos setores de atuação da Educação Física, mesmo que a maior porcentagem de egressos apresentem vínculos com carteira assinada, uma boa parte destes trabalhadores atua como autônomos e esta configuração pode gerar perda de direitos para os profissionais da área.

Após a formatura, 65,9\% dos egressos tiveram inicio imediato de sua atividade profissional no mercado de trabalho, 23,2\% levou menos de um ano para conseguir um emprego e 6,1\% conseguiu encontrar um emprego de dois a três anos após a formatura. Podemos observar então que o mercado de trabalho tem oferecido vagas de emprego para os egressos recém-formados, já que a maior parte da amostra teve inicio imediato de sua atividade profissional quando formados, semelhante a este 
achado Piccoli (2006) encontrou que 80\% dos egressos de educação física da Feevale não tiveram dificuldades para conseguir um emprego após a conclusão do curso.

$6,1 \%$ dos egressos da UFMG levaram até dois anos para encontrar um emprego, tempo relativamente longo, já que parte dos egressos da pesquisa saiu da universidade e foram inseridos diretamente no mercado de trabalho. Algumas dificuldades encontradas pelos egressos da educação física para conseguir um emprego são relatadas na pesquisa de Salles et al. (2015), os bacharéis elencaram o excesso de estagiários em postos de trabalho ou profissionais sem a devida habilitação, ocupando - lugar de um profissional formado; a falta de conhecimento especifico para desenvolver adequadamente suas ocupações profissionais e a saturação do mercado de trabalho. Os licenciados reconhecem que a dificuldade em encontrar emprego pode estar relacionado com a desvalorização do professor perante a sociedade; com as deficiências curriculares na formação profissional e a escassez de concursos para atuação como professor efetivo. Desta forma, encontramos em nossa pesquisa uma maior porcentagem de egressos iniciando suas atividades profissionais imediatamente após a formatura, mas como exposto, sabemos das inúmeras dificuldades e precariedades encontradas para conseguir um emprego digno e que the proporcione a capacidade de uma intervenção adequada.

Buscamos investigar também a jornada de trabalho e número de locais onde os egressos atuam. Foi encontrado que 59,7\% dos egressos atuam em um local de trabalho, 30,6\% atuam em dois empregos e 9,7\% dos egressos trabalham em três empregos, ou seja, 40,3\% dos egressos trabalham em mais de um emprego.

O fato dos egressos trabalharem em mais de um emprego pode estar relacionado com a questão salarial, muitos profissionais da educação física ainda necessitam realizar uma jornada de trabalho semanal múltipla para conseguir um salário digno, porém, nem sempre esta jornada de trabalho é saudável para o profissional que pode futuramente desenvolver problemas de saúde e até mesmo abandonar a profissão por exaustão.

Quando se trata da jornada de trabalho semanal, os valores encontrados mostram que $41,5 \%$ dos egressos realizam uma jornada de 30 a 40 horas por semana, 29,3\% trabalham entre 20 e 30 horas semanais, 11\% trabalham entre 10 e 20 horas por semanas, apenas $8,5 \%$ trabalham mais de 40 horas em uma semana e 1,2\% têm uma jornada inferior a 5 horas semanais. Palma et al. (2007) apresentaram resultados semelhantes quando pesquisaram a jornada de trabalho em academias de ginástica, foi encontrado que mais da metade da amostra possuía mais de um emprego, e a média de horas trabalhadas semanalmente pelos profissionais foi de 42 horas, resultados semelhantes aos encontrados nesta pesquisa, os resultado que diferiram foi a porcentagem de profissionais que trabalham mais de 40 horas semanais, onde $34,5 \%$ trabalhava mais de 50 horas por semana.

Analisando os resultados obtidos das questões "número de locais de trabalho" e "jornada de trabalho semanal" podemos perceber que os egressos de Educação Física da UFMG tem uma jornada de trabalho de acordo com o previsto na constituição brasileira, a norma geral prevê uma jornada de 8 horas diárias ou 44 horas semanais e $82 \%$ dos egressos de educação física da UFMG trabalham até 40 horas semanais, desta forma, podemos dizer que a jornada de trabalho para este grupo está em consonância com as leis trabalhistas e garantindo ao profissional uma jornada semanal saudável. $8,5 \%$ dos egressos trabalham mais de 40 horas semanais, sendo 
considerado trabalho extraordinário segundo a Constituição Federal, (Art.7ำ XIII), e no (Art. 58 da CLT) (MORAIS, 2011). Grandes jornadas de trabalho não são saudáveis ao profissional, pois compromete o tempo para o lazer, autocuidado com a saúde, convívio familiar, dedicação a projetos pessoais, etc., conduzindo a um comprometimento com a qualidade de vida do egresso e gerando um desgaste proveniente do excesso de horas realizando esforço físico e mental, podendo gerar agravos à saúde (MENDES e AZEVEDO, 2014).

\section{Gráfico 2- Jornada de trabalho semanal dos egressos do curso de Educação Física da UFMG}

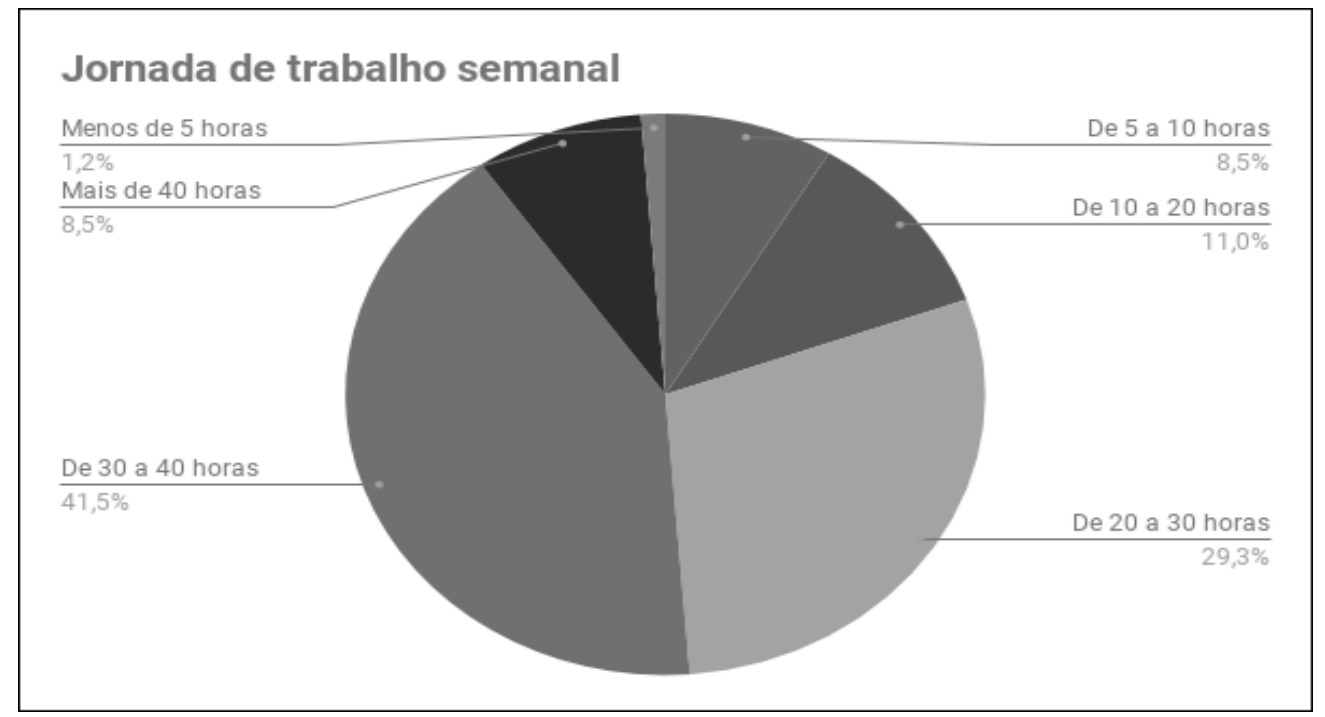

Fonte: Elaborado a partir dos dados da pesquisa (2018)

A forma como os egressos da educação física são remunerados mostra que $56,1 \%$ têm um salário fixo, 35,4\% recebe através de horas-aulas realizadas durante o mês. Quando se considera a renda mensal bruta dos egressos, percebeu-se que a maioria deles $(23,8 \%)$ tinha rendimento mensal entre $R \$ 2.001,00$ a $R \$ 3.000,00$, indo ao encontro com o rendimento bruto de outras pesquisas sobre a remuneração do profissional da educação física, Salles et al. (2015) encontrou que a maioria dos egressos de sua pesquisa recebiam até 3 salários mínimos mensais. 12,5\% dos egressos desta pesquisa recebem de $R \$ 0,00$ a $1.000,00$, de $R \$ 1.001,00$ a $R \$$ $2.000,00$ são $15 \%$ dos egressos, outros $15 \%$ recebem mensalmente de $R \$ 3.001,00$ a $R \$ 4.000 .00,16,3 \%$ recebem de $R \$ 4.001,00$ a $R \$ 5.000,00,6,3 \%$ recebem de $R \$$ $5.001,00$ a $R \$ 6.000,00,1,3 \%$ dos egressos recebem entre $R \$ 6.001,00$ a $R \$ 7.000,00$, $2,5 \%$ recebem de $R \$ 7.001,00$ a $R \$ 8.000,00$ e por fim $7,5 \%$ dos egressos recebem acima de $R \$ 8.001,00$ mensalmente.

Os valores encontrados mostram a baixa remuneração recebida pelo profissional de educação física no Brasil, levando em consideração a jornada de trabalho e ao número de locais de emprego que estes profissionais atuam, já que $65,5 \%$ dos egressos recebem um valor inferior a $R \$ 4.000,00$ por mês e apenas $17,6 \%$ recebem salários acima de $R \$ 5.000,00$ por mês.

A baixa remuneração mostra que $42 \%$ dos egressos estão insatisfeitos com os seus salários e $11 \%$ estão muito insatisfeitos, $39,5 \%$ se sentem satisfeitos com a remuneração recebida, ou seja, $53 \%$ dos egressos não estão satisfeitos com o valor recebido pelo seu trabalho, demonstrando que a questão salarial é um fator negativo 
para o profissional da Educação Física. Alguns estudos corroboram com os resultados encontrados sobre remuneração e insatisfação com o salário, Silva e Nunez (2009) encontraram que a maior insatisfação dos professores de educação física de uma rede municipal de ensino de Campo Grande é em relação ao salário recebido, e que 61,3\% dos professores precisavam trabalhar em mais de um emprego para complementar a renda.

Furtado e Santiago (2015) relatam que a média de salário do egresso formando na Universidade Federal de Goiás é de $\mathrm{R} \$ 1.788,11$, abaixo da média encontrada neste e em outros estudos, levando os profissionais a se submeterem a uma sobrecarga de trabalho em busca de uma garantia mínima de rendimentos que atendam suas necessidades. Piccoli (2006) encontrou que 58,5\% dos egressos de sua pesquisa afirmam que o cargo ocupado não era compatível com o salário recebido, sendo necessário atuar em outros locais de trabalho para completar os rendimentos. Salles et al. (2015) também descreve a manifestação dos profissionais da educação física em relação a remuneração, onde os mesmos consideram desmotivador para trabalhar. Koga et al. (2015) aponta que um dos fatores que podem levar os profissionais a desenvolverem o burnout, ou síndrome do esgotamento profissional, é a insatisfação com a remuneração somado a outros fatores do local de trabalho.

Desta forma, percebemos que o fator salarial é um dos pontos negativos que mais desenvolvem insatisfações com a profissão da Educação Física, já que os profissionais necessitam enfrentar longas jornadas de trabalho para conseguirem a renda que desejam. Entretanto, os profissionais apresentam um nível de satisfação com o local de trabalho positivo, já que $42 \%$ dos egressos estão satisfeitos com a sua atual ocupação, $25,9 \%$ estão parcialmente satisfeitos, $22 \%$ estão muito satisfeitos e $6,2 \%$ estão insatisfeitos. Apesar dos egressos demonstrarem descontentamento com o salário, a maioria está satisfeita com o local onde está trabalhando, sendo o valor em porcentagem de "insatisfeitos" significativamente inferior aos "satisfeitos". Apenas 3,7\% dos egressos gostariam de mudar de profissão, mostrando que a maioria dos egressos gosta de trabalhar com as áreas de atuação da Educação Física. Segundo Coda (1990), a manutenção de certos níveis de satisfação no trabalho podem contribuir para uma melhor qualidade de vida. Desta forma, entendemos que as insatisfações dos egressos da educação física estão relacionadas a questões salariais e longas jornadas de trabalho, já que em relação aos locais de trabalho os egressos se sentem satisfeitos com os seus empregos.

Os egressos que não trabalham na área de sua formação acadêmica relatam que os motivos para não exercerem sua profissão foram: 38,1\% encontraram melhores oportunidades em outras áreas de atuação, 14,3\% acha a profissão financeiramente desestimuladora, 14,3\% descobriu não gostar de trabalhar com educação física e 9,5\% não encontraram emprego na área.

É nítida a insatisfação dos egressos quanto à falta de valorização da profissão e os baixos salários, esses aspectos somados ao não reconhecimento da sociedade quanto à importância da profissão e as frustrações com o trabalho levam os egressos ao distanciamento ou até mesmo abandono da profissão (FURTADO e SANTIAGO, 2015).

Deste modo, pode-se observar que a forma como os egressos atuam no mercado de trabalho e a profissão Educação Física apresentam pontos importantes que devem ser debatidos e deliberados para que ocorra o crescimento e desenvolvimento desta 
ocupação, beneficiando seus profissionais e a sociedade que demanda de seus serviços.

\section{CONSIDERAÇÕES FINAIS}

Os resultados encontrados manifestam as características dos egressos formados em Educação Física na UFMG, no qual a maioria dos sujeitos é do sexo feminino (68\%), com $50 \%$ dos indivíduos pertencentes à raça branca, onde a grande parte desta amostra (70\%) reside em Belo Horizonte, Minas Gerais, com idade variando entre $22 \mathrm{e}$ 40 anos, entretanto, 79\% dos egressos apresentam idade inferior a 30 anos, podendo ser considerado um perfil de trabalhador jovem no mercado de trabalho.

Também foram encontrados nesta pesquisa os locais de atuação onde os egressos mais se inserem após a formatura. Sabemos que, 79\% dos egressos estão atuando em sua área de formação acadêmica, sendo que $22 \%$ estão atuando como professores de Educação Física e inseridos nas escolas, 17,4\% dos egressos trabalham como personal trainer, 14,4\% trabalham em academias de ginástica, 12,9\% trabalham em escolinhas de esporte, 6,8\% trabalham com treinamento funcional e/ou crossfit, 5,3\% com alto rendimento esportivo e 3,8\% trabalham com recreação. Sendo as funções de professor (a) de educação física e personal trainer as ocupações mais aderidas pelos egressos no mercado de trabalho.

Pensando na formação profissional recebida e nas exigências mercadológicas condicionadas aos egressos da Educação Física, encontramos que em sua maioria os egressos optaram por realizar apenas uma graduação, 50\% destes se formaram como bacharéis em Educação Física, $30 \%$ são licenciados e $20 \%$ realizou as duas graduações, sendo um valor relativamente baixo pensando que para concluir as duas graduações não se fazem necessário à realização de um novo processo seletivo. Em relação à pós-graduação, encontramos que 35\% dos egressos optaram por realizar pós-graduação latu sensu e stricto sensu, sendo que $65 \%$ da amostra ainda não realizou pós-graduação. Destes egressos que optaram pela realização da pósgraduação 59,5\% teve preferência pela especialização, 33\% optaram pelo mestrado e $7,1 \%$ realizaram doutorado. Através do cruzamento das variáveis renda bruta mensal dos egressos e pós-graduação, encontramos que os indivíduos que realizaram pósgraduação tendem a receber maiores salários quando comparados aos indivíduos que não a realizaram, sendo então o aprofundamento na formação profissional com a educação continuada uma das possíveis exigências mercadológicas acima dos egressos.

Se tratando da dificuldade em encontrar emprego pelos egressos após a formatura obtivemos resultados positivos, já que $65,9 \%$ dos egressos tiveram inicio imediato de sua atividade profissional no mercado de trabalho, não constatando impedimentos para encontrar emprego como profissional da Educação Física. Entretanto, quando investigado os egressos que não estão atuando na sua área de formação acadêmica, descobrimos que 9,5\% deles não estão atuando na área porque não encontraram um emprego como profissional da Educação Física. Esta pesquisa não se preocupou em aprofundar a investigação sobre os motivos que geram dificuldades em encontrar emprego como profissional da Educação Física, desta forma, fica aberta a possibilidade para novas pesquisas sobre tal assunto. 
As tendências que encontramos para o atual mercado de trabalho da Educação Física nos mostram que o profissional desta área atua em maior parte no setor privado (62,9\%). Em relação aos vínculos empregatícios 36\% dos egressos estão empregados com carteira assinada, enquanto $27 \%$ são autônomos. Se tratando do rendimento bruto mensal dos egressos encontramos que a maioria deles $(23,8 \%)$ tem rendimento mensal entre $R \$ 2.001,00$ a $R \$ 3.000,00$ e 59,7\% dos egressos atuam em apenas um local de trabalho, entretanto, quando relacionamos a renda bruta mensal e o número de locais de trabalho onde os egressos atuam encontramos resultados semelhantes aos expostos na literatura, com a necessidade de complementar a renda os egressos que atuam em mais de um emprego conseguem concentrar maiores salários.

Este estudo apresentou limitações que devem ser ressaltadas. $O$ tamanho da amostra, que ao se apresentar em número reduzido, permite considerar os resultados encontrados apenas para a população em questão, para uma analise mais abrangente do mercado de trabalho da Educação Física, faz se necessário uma pesquisa com maiores proporções de participantes e abrangendo outras regiões. $O$ fato de 0 questionário ser semiestruturado e ter sido aplicado em uma plataforma virtual nos limitou de encontrar um maior numero de dados, caso a pesquisa fosse realizada em forma de entrevista e pessoalmente, talvez conseguiríamos extrair mais informações dos egressos.

Conforme citado anteriormente, esta pesquisa deixa abertas as possibilidades para novos estudos sobre os egressos da Educação Física. Sugerem-se novas pesquisas abordando as diretrizes curriculares para os cursos de Educação Física, que como apresentado neste estudo mostram diversas lacunas na formação dos profissionais desta área e que podem prejudicar a atuação dos mesmos no mercado de trabalho. As questões sobre gênero podem ser abordadas de diversas formas e devem ser pesquisadas com maior profundidade, já que nesta pesquisa não conseguimos responder se a predominância das mulheres atuando na área da Educação Física é verídica e as possíveis novas configurações que isto pode causar, entre outros pontos importantes sobre o assunto que devem ser analisados. Sugerem-se também novas pesquisas sobre a pós-graduação, pois, apesar deste trabalho ter encontrado novas informações sobre o assunto ficam lacunas sobre os egressos que ainda não realizaram a educação continuada, não conseguimos responder os motivos pelo qual os egressos optaram por não realizar a pós-graduação e as consequências disto. Espera-se que os resultados destas pesquisas contribuam para a melhoria e qualificação dos cursos de graduação em Educação Física, permitindo que os profissionais sintam segurança na sua atuação e ofereça a sociedade uma intervenção satisfatória.

\section{REFERÊNCIAS}

ALMEIDA, L. de; FENSTERSEIFER, P.E. Professores de Educação Física: duas histórias, um só destino. Revista Movimento, Porto Alegre: ESEF/UFRGS, v.13, n.2, p.13-36, mai./ago., 2007.

BOTOMPE, S. P. \& KUBO, O. M. Responsabilidade social dos programas de pós-graduação e formação de novos cientistas de nível superior. Revista Interação em Psicologia, 2002.

CARVALHO, J. J. Inclusão étnica e racial no ensino superior: um desafio para as universidades brasileiras. Série Antropologia. Brasília: UnB, n. 382, 2005.

CHAHAD, J. P. Z. Tendências recentes no mercado de trabalho: pesquisa de emprego e desemprego. São Paulo, Perspect, 2003. 
CODA, R. Satisfação no trabalho e políticas de RH: uma pesquisa junto a executivos. In: BERGAMINI, C.W.; CODA, R. (orgs.) Psicodinâmica da vida organizacional: motivação e liderança. São Paulo: Pioneira, 1990. Cap.4.

EMEC. Detalhes dos cursos. Disponível em: https://emec.mec.gov.br/emec/consulta-cadastro/detalhescurso/d96957f455f6405d14c6542552b0f6eb/NDA=/9f1aa921d96ca1df24a34474cc171f61/MjE= Acesso em: 09 dez. 2019.

FURTADO, R. P., \& SANTIAGO, L. P. Educação Física e trabalho: considerações a respeito da inserção profissional de egressos da FEF-UFG. Revista Brasileira de Educação Física e Esporte, v.29, Abril de 2015.

GIL, Antonio Carlos. Como elaborar projetos de pesquisa. 6. ed. São Paulo: Atlas, 2008.

GONDIM, S.M.G. Perfil profissional e mercado de trabalho: relação com a formação acadêmica pela perspectiva de estudantes universitários. Estudos de Psicologia, v.7, p.299- 309. Salvador, 2002.

IPEA. Instituto de Pesquisa Econômica Aplicada. Salários no setor público versus salários no setor privado no Brasil. Brasília: IPEA, 2009.

JACOB, A. L.; SOUZA, M. S.; PRIETTO, A. L. A divisão licenciatura/bacharelado no curso de Educação Física: o olhar dos egressos. Movimento, Porto Alegre, v. 23, n. 2, 2017.

JAKOBSEN, K. et al. Mapa do trabalho informal. São Paulo: CUT/FPA, 2000.

KRUG, H. N.; KRUG, R. de R. Os diferentes motivos da escolha da licenciatura em Educação Física pelos acadêmicos do CEFD-UFSM. Revista Digital Lecturas: Educacíon Física y Deportes, Buenos Aires, $n$. 123, p. 1-8, 2008.

LEITE, J.O. et al. Perfil atual da formação do profissional em Educação Física no Brasil. Espírito Santo, In: CONBRACE, 19, CONICE, 6. 2015.

LIMA, E.; MACHADO, L. A evasão discente nos cursos de Licenciatura da Universidade Federal de Minas Gerais. Educação Unisinos. São Leopoldo. v. 18, n. 2, 2013.

LOUSADA, A. C. Z. ; MARTINS, G. A. Egressos como fonte de informação a gestão dos cursos de Ciências Contábeis. Revista Contabilidade \& Finanças, São Paulo/USP, v. 1, n. 37, 2004.

MORSCHBACHER, M. Reformas curriculares e formação do (novo) trabalhador em educação física: a subsunção da formação à lógica privada/ mercantil. Dissertação de Mestrado. ESEF/UFPel, Pelotas (RS), 2012.

MASCHIO, V.; SILVA, A. R.; BASEI, A. P.; ILHA, F. R. da S.; KRUG, H. N. As motivações para a escolha do curso de licenciatura em Educação Física: um diálogo com acadêmicos em formação inicial. In: SEMINÁRIO INTERNACIONAL DE EDUCAÇÃO, 13, 2008, Cachoeira do Sul. Anais... Cachoeira do Sul: Ulbra, 2008.

MELO, S. L., \& BORGES, L. O. A Transição da universidade ao mercado de trabalho na ótica do jovem. Psicociência e profissão, v.27, p.376-395, 2007.

MENDES, A. D.; AZEVEDO, P. H. O trabalho e saúde do educador físico em academias: Uma contradição no cerne da profissão. Revista Brasileira de Educação Física e Esporte, v. 28, n. 4, São Paulo, 2014.

MINISTÉRIO DA CIÊNCIA E TECNOLOGIA. Plano de ação em ciência, tecnologia e inovação: Principais resultados e avanços. Brasília: Ministério da Ciência e Tecnologia. 2010.

PALMA, A.; JARDIM, S.; LUIZ, R. R.; SILVA FILHO, J. F. Trabalho e saúde: o caso dos professores de educação física que atuam em academias de ginástica. Cadernos IPUB, UFRJ, 2007.

PICCOLI, J.C.J.; MENEZES, F. C. L.; O perfil do egresso do curso de Educação Física do Centro Universitário Feevale. Lect Educação Física Deportes. Novo Hamburgo, 2006.

PRADO, A. R., CARVALHO, Y.M. Formação em Educação Física: Experiências de integração ensinoserviço na atenção básica em saúde. Movimento, Porto Alegre, v. 22, n. 2, 635-646, abr.jun. de 2016.

RAZEIRA, Mauricio Berndt et al. Os motivos que levam à escolha do curso de licenciatura em Educação Física e as pretensas áreas de atuação. Revista Mackenzie de Educação Física e Esporte, São Paulo, v. 13, n. 2, p. 124-136, jul./dez. 2014. 
SALLES, W.N., Farias, G.O. \& Nascimento, J.V. Inserção profissional e formação continuada de egressos de cursos de graduação em Educação Física. Revista Brasileira de Educação Física e Esporte, v. 29, n. 3, p. 475-86, 2015.

SANTOS, C. M. Educação continuada- Faculdade de Educação - Universidade Bandeirante de São Paulo. São Paulo, 1999. (Dissertação de Mestrado).

SCHWARTZMAN, S. \& CASTRO, M. H. M. A trajetória acadêmica e profissional dos alunos da USP. Documento de Trabalho 2/91. São Paulo: Núcleo de Pesquisas sobre o ensino superior da Universidade de São Paulo, 1991.

SILVA, J. V. P.; NUNEZ, P. R. M. Qualidade de vida, perfil demográfico e profissional de professores de educação física. Pensar a Prática, Goiânia, v. 12, n. 2, 2009.

STEINHILBER, J. Inserção Mercadológica dos profissionais de educação física no estado do Rio de Janeiro. In: CONGRESSO BRASILEIRO DE CIENCIAS DO ESPORTE, XI., 1999, Caxambu. Anais..., Colégio Brasileiro de Ciências do Esporte, v.2, 1999.

TAFARREL, C. N. Z. A Formação de professores de educação física e a licenciatura ampliada. In: SEMANA DE EDUCAÇÃO FÍSICAUUFMS, 17, 2012, Campo Grande (MS); JORNADA DE INICIAÇÃO CIENTIFICA DO CURSO DE EDUCAÇÃO FíSICAJUFMS, 4., 2012, Campo Grande (MS). 38 f. Trabalho apresentado em evento.

TANI, Go. Cinesiologia, Educação Física e Esporte: ordem emanente do caos na estrutura acadêmica. Motus Corporis. Rio de Janeiro: UGF, v. 3, n. 2, dezembro, 1996.

TRINDADE, P. dos S. Perfil sócio-econômico e vocacional dos alunos de Educação Física da Universidade Federal Rural do Rio de Janeiro. CONGRESSO INTERNACIONAL DE EDUCAÇÃO FíSICA, 11, 1996. Paraná: Federação Internacional de Educação Física (FIEP), 1996.

VARGAS, Michely de Lima Ferreira. Ensino superior, assistência estudantil e mercado de trabalho: um estudo com egressos da UFMG. In: Avaliação, Campinas, v.16, n.1, mar. 2011.

Data da submissão: 31/10/2019

Data da aprovação: 20/11/2019 